\title{
Using DMSP Night-Time Imagery to Evaluate Lighting Practice in the American Southwest
}

\author{
Christian B. Luginbuhl \\ United States Naval Observatory, Flagstaff Station, PO Box 1149, \\ Flagstaff AZ 86002 USA
}

\begin{abstract}
The U.S. Defense Meteorological Satellites provide an opportunity to measure the uplight produced by artificial lighting on the ground. In this study DMSP data are used to measure the integrated atdetector radiance of a number of communities in the American Southwest in an attempt to evaluate the effectiveness of outdoor lighting codes. Use of DMSP data in this manner is complicated by many factors, and some of these are briefly discussed.
\end{abstract}

\section{Introduction}

The U.S. Air Force Defense Meteorological Satellite Program (DMSP) satellites orbit Earth in sun-synchronous, low-altitude polar orbits. One orbit is oriented such that the satellite circles the globe approximately over the sunrise/sunset terminator, the other passes over near noon and midnight. The principle purpose of the program is to monitor cloud conditions, but the night-time observations of city lights are what have the attention of the astronomical community.

Other workers have begun using DMSP data to measure uplight produced by cities, including Isobe \& Hamamura (1998), Isobe (1998), Falchi \& Cinzano (1999) and Cinzano et al. (2000). The present study evaluates the possibility of using DMSP data to measure the overall success of light pollution control efforts. Tucson and Flagstaff, Arizona, are two cities in the American Southwest that have a substantial history of light control efforts through outdoor lighting codes. Are these codes working?

\section{This Study}

The image used in this study is a cloud-free composite of the United States built from many DMSP midnight passes during the dark of the lunar cycle in March 1996 and January-February 1997 (Elvidge et al. 1999).

Brightnesses were measured from this image for a sample of towns and cities in Arizona, Utah, Nevada and New Mexico, covering a range in population from under 2000 to almost 2.5 million. The radiance values were summed within rectangular regions around each municipality.

Population figures were taken from the U.S. Census Bureau website, where estimated figures for July 1996 (released in June 1999) are listed. These figures are shown in Table 1 and Figure 1. 
Table 1. Radiance $\left(10^{-10}\right.$ watts $\left./ \mathrm{cm}^{2} / \mathrm{sr} / \mu \mathrm{m}\right)$ and 1996 Population for Southwestern U.S. Cities

\begin{tabular}{|c|c|c|c|c|}
\hline Fig. 1 & City & State & Population & Radiance \\
\hline $\mathrm{CaV}$ & Camp Verde & $\mathrm{AZ}$ & 7552 & 3616 \\
\hline $\mathrm{ChV}$ & Chino Valley & $\mathrm{AZ}$ & 6588 & 1714 \\
\hline Cot & Cottonwood & $\mathrm{AZ}$ & 6937 & 9941 \\
\hline Dou & Douglas & $\mathrm{AZ}$ & 15015 & 28288 \\
\hline Flg & Flagstaff & $\mathrm{AZ}$ & 55094 & 31110 \\
\hline $\mathrm{GiB}$ & Gila Bend & $\mathrm{AZ}$ & 1695 & 10447 \\
\hline Hol & Holbrook & $\mathrm{AZ}$ & 5398 & 5951 \\
\hline Kin & Kingman & $\mathrm{AZ}$ & 17270 & 29998 \\
\hline LHC & Lake Havasu City & $\mathrm{AZ}$ & 39503 & 18912 \\
\hline Phx & Phoenix metro $^{a}$ & $\mathrm{AZ}$ & 2427230 & 1666182 \\
\hline Pre & Prescott & $\mathrm{AZ}$ & 49760 & 29693 \\
\hline Sed & Sedona & $\mathrm{AZ}$ & 9109 & 5722 \\
\hline $\mathrm{SiV}$ & Sierra Vista & $\mathrm{AZ}$ & 37434 & 28307 \\
\hline Tuc & Tucson $b$ & $\mathrm{AZ}$ & 472305 & 396799 \\
\hline TuM & Tucson metro ${ }^{c}$ & $\mathrm{AZ}$ & 729479 & 396799 \\
\hline Wic & Wickenburg & $\mathrm{AZ}$ & 5312 & 4020 \\
\hline Wcx & Willcox & $\mathrm{AZ}$ & 3533 & 4005 \\
\hline Wil & Williams & $\mathrm{AZ}$ & 2706 & 3588 \\
\hline Win & Winslow & $\mathrm{AZ}$ & 10420 & 10257 \\
\hline Bly & Blythe & $\mathrm{CA}$ & 12982 & 14855 \\
\hline LVN & Las Vegas $^{d}$ & NV & 577904 & 1086814 \\
\hline Mes & Mesquite & NV & 6200 & 22970 \\
\hline Alb & Albuquerque ${ }^{e}$ & NM & 425526 & 438288 \\
\hline $\mathrm{LaC}$ & Las Cruces & NM & 74779 & 55252 \\
\hline LVM & Las Vegas & NM & 16437 & 18365 \\
\hline Ros & Roswell & NM & 47559 & 45081 \\
\hline StF & Santa Fe & NM & 66522 & 67701 \\
\hline StG & St George & UT & 42763 & 43521 \\
\hline
\end{tabular}

\footnotetext{
${ }^{a}$ Includes Apache Jct, Avondale, Chandler, El Mirage, Fountain Hills, Gilbert, Glendale, Goodyear, Guadalupe, Litchfield Park, Mesa, Paradise Valley, Peoria, Scottsdale, Surprise, Tempe, Tolleson, Youngtown.

${ }^{b}$ Includes Oro Valley, South Tucson.

${ }^{c}$ Includes $95 \%$ of Pima County population.

${ }^{d}$ Contains three saturated pixels. Includes Henderson, North Las Vegas.

${ }^{e}$ Includes Corrales.
} 

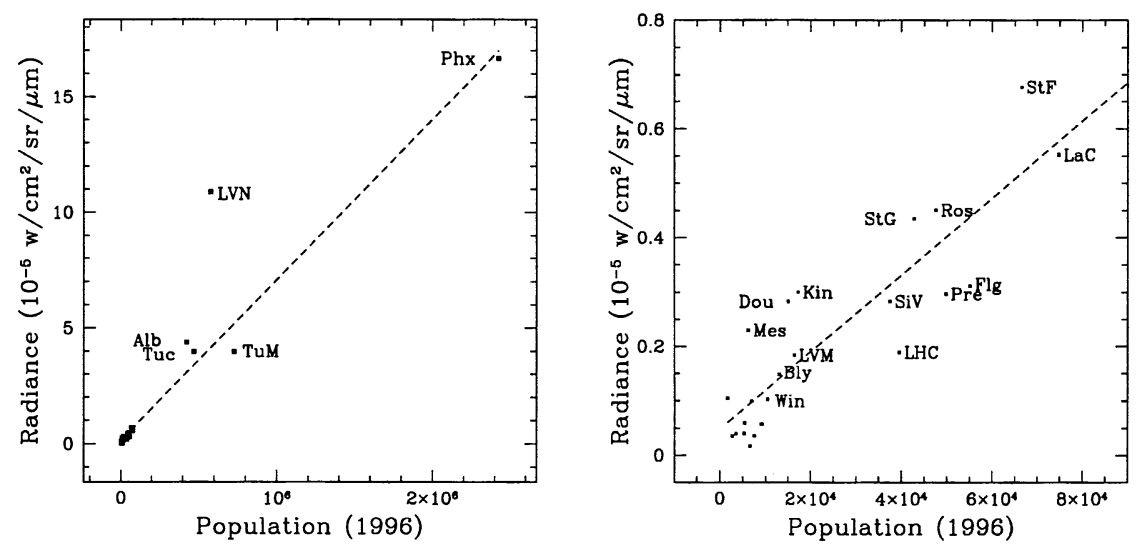

Figure 1. Integrated radiance vs. population for all measured cities (left) and smaller cities (right). The dashed line is a first-order fit to the data below 80,000 population. Letter abbreviations are in Table 1.

\section{Discussion}

Though there are many uncertainties in these data and their interpretation (see below), the measured integrated radiance of Flagstaff, AZ falls near the lower limit for cities of similar size. Flagstaff has had a long history of outdoor lighting controls, beginning in 1958 with the first lighting code addressing astronomical interests anywhere in the world, and followed by regular updates to the present time. The integrated radiance of Flagstaff is approximately that of an average town of population about 37,000 , or about $67 \%$ as much as an average city of its size in these data.

But other communities without strict lighting codes appear fainter than the average as well (e.g. Prescott, AZ), and this leaves the question whether the moderate brightness of Flagstaff can be attributed to its lighting codes.

Another city with a similar long history of outdoor lighting codes is Tucson. There are few cities of similar size in the region against which to compare its brightness, and therefore the brightness of an "average" city of this size is hard to define. In Figure 1, the Census Bureau population figure and the integrated DMSP radiance place Tucson close to the line connecting the small cities to the single large metropolitan area of Phoenix; it also appears comparable to the similarly sized Albuquerque. But Tucson has a large polulation in adjacent areas of Pima County, outside the city limits on which the official population is based. Tucson planners estimate that presently the population of the Tucson metropolitan region is $95 \%$ of the Pima County population. Applying this fraction to the Census Bureau 1996 estimate for Pima County $(767,873)$ would put Tucson at 729,479 , and therefore considerably fainter per capita.

There is scant indication in these figures for a decreasing uplight per capita as population increases, as seen by Falchi \& Cinzano (1999), nor is there any apparent tendency to decreased per capita output with increasing population, 
as reported by Garstang (1986). A first-order fit to the cities of less than 80,000 nearly exactly intercepts the largest and brightest city measured.

\subsection{Sources of Error}

Assuming there are no residual clouds in the composite image, and neglecting photometric calibration uncertainties in the DMSP photometric equipment and processing, the following are some of the effects that will influence the per capita apparent brightness of cities in the DMSP data:

Population Uncertainties. Population figures are uncertain for many communities, since what the Census Bureau defines as a given city does not always correspond with what appears to be the city extent in the DMSP image. The example of Tucson presented here, where the true figures may be more than $50 \%$ higher than Census Bureau figures, may be generally indicative of the magnitude of this source of error. A proper approach will require a detailed community-by-community population analysis.

Angular Dependence. The light emitted from cities is not likely to be independent of direction. Reflected uplight might be approximately lambertian (ignoring blocking effects) but direct uplight is likely to have strong angular dependencies. Garstang (1986) assumes an intensity dependence of direct uplight proportional to the fourth power of the zenith angle. Although the raw DMSP scans contain observations over a range of zenith angels on an east-west line, it is not clear how such a limited sample of altitude and azimuth measures can be applied to evaluating the entire upward hemisphere.

Ground-Level Obscuration. Variable amounts of obscuration from vegetation and structures will affect the apparent brightness of cities as viewed from different angles. This effect may increase toward the horizon but it has not been measured. The degree of this effect may also be correlated with city size as larger cities have taller buildings.

Albedo Variations. Varying reflectivity of the ground, the relation of such variation to lighting use, and the presence or absence of snow cause further uncertainities. These effects, particularly of snow, could be large.

Extinction. The zenith angle of DMSP observations as viewed from the ground varies from $0 \mathrm{deg}$ to about $60 \mathrm{deg}$, leading to a 1 to 2 range in airmass between the source and detector. Atmospheric extinction coefficients vary from approximately $0.35 \mathrm{mag} /$ airmass near the blue limit of the detector to 0.1 $\mathrm{mag} /$ airmass or less near the red limit. This effect has not been removed from these data, and sufficient information may not be available to do it.

\section{References}

Cinzano, P., Falchi, F., Elvidge, C.D., Baugh, K.E. 2000, MNRAS, 318, 641-657

Elvidge, C. et al. 1999, Remote Sensing of Environment, 68, 77

Falchi, F. and Cinzano, P. 2000, Mem. Soc. Astro. It., 71, 139-152

Garstang, R. H. 1986, PASP 98, 364

Isobe, S. 1998, paper presented at Division 4 meeting of the CIE, 24 October 1998

Isobe, S. and Hamamura, S. 1998, ASP Conf. Ser. 139, 191 